FOLIA SCANDINAVICA

VOL. 21 POZNAŃ 2016

DOI: $10.1515 /$ fsp-2016-0048

\title{
LITERATURE
}

\section{NÅGRA TANKAR OM NORDISK BARNLITTERATUR OCH DESS ÖVERSÄTTNING UR ETT POLSKT PERSPEKTIV}

\author{
HANNA DYMEL-TRZEBIATOWSKA \\ University of Gdańsk
}

ABSTRACT. The article explores two aspects of translations of Nordic children's literature, which is more and more often defined by its authors as aimed at all readerships with no respect to age (allalderslitteratur). This stance may affect the theory of translation in reference to the category of the implied reader, which will have to be reconsidered. The concept of allage literature is presented in the article as a solution to long academic discussions about the presence of an adult implied reader of children's literature. The other perspective shows the presence of Scandinavian picturebooks on the Polish book market which have been published within the latest decade (e.g. by Svein Nyhus, Gro Dahle, Pernilla Stalfelt, Pija Lindenbaum, and Ulf Nilsson). These books are brave, taboo-breaking and translated without purifications, which refutes Elżbieta Zarych's (2016) observations about the rules and mechanisms which are prevalent, i.e. that translators are still expected to mitigate and omit painful moments. The final part combines two aspects - the above-mentioned translations are free of adaptations, but it is difficult to assess whether the translators have taken into account the postulates of Scandinavian authors and their ambition to create all-age literature. Answers to the questions posed at the end (e.g. if the books are created for all, should they be translated for all?) might complete the translation studies with important and future-oriented insights.

\section{VEM ÄR BARNBÖCKER TILL?}

Förr i tiden var det mycket lättare. Det fanns böcker för vuxna och det fanns böcker för barn, och ingen behövde ifrågasätta den självklara uppdelningen. Barnboken lästes för och av barn, och vuxenboken lästes av vuxna, om man bortser från undantag då publiken blandades - men det var snarare praxis att vuxna då hade rätt att läsa barnlitteratur än tvärtom. 
När man började se närmare på olika teoretiska frågor, visade det sig dock att det inte längre var tydligt vilken bok som var för barn och vilken som var för vuxna. Och när det kom allt fler teorier inom barnboksforskningen, slutade akademikerna att vara eniga om barnlitteraturens kriterier. De tvistade om vad som borde vara allra viktigast: innehållet, formen eller läsaren? Och barnläsaren, som varit så självklar som kriterium genom åren, blev plötsligt problematisk. Så småningom dök tanken upp att barnböcker riktar sig samtidigt till både barn och vuxna. Detta betraktas idag av somliga även som barnlitteraturens immanenta egenskap, den som skiljer denna genre från allmän litteratur. Inom denna diskussion kan man nämna några framstående personer som t.ex. Zohar Shavit, Barbara Wall, Perry Nodelman och Sandra Beckett.

Shavits (1986) grundtanke går ut på att barnböcker läses synkront i två litterära system av vuxna och barn. Och att endast de verk som uppskattas och accepteras av vuxna, och som hon kallar för AMBIVALENTA, kan införas i barnsystemet. Exempel på det är klassiker som Alice $i$ Underlandet eller Nalle Puh. Shavit hävdar följande:

Only by addressing the text both to children and to adults and by pretending it is for children can the writer make possible the dual acceptance of the text. Adults are willing to accept it as a text for children because they are able to read it, due to its level of "sophistication" ("sophisticated" for the children of course). The "stamp of approval" on the other hand, apparently opens the way for acceptance of the text by the children's system (though children do not realize the text in full and are not even supposed to do so, according to adult criteria). (Shavit, 1986: 67)

Wall (1991) erbjuder en populär, tredelad indelning: 1. DUBBELT TILLTAL (detta ses som något negativt, som hör till det förflutna, då författaren vände sig till vuxna över barnets huvud), 2. ENSTAKA TILLTAL (författaren gjorde sitt bästa för att skriva enbart för barn), 2. JÄMLIKT TILLTAL i positiv bemärkelse, vilket innebär att en bok vänder sig till två implicita läsare samtidigt och på lika villkor. Hon poängterar: "Narrators using single address, double address, or a fusion of the two, dual address, can be shown to speak respectively to single, double or dual audiences." (Wall, 1991: 9)

Nodelman (2008) ifrågasätter den skarpa uppdelningen mellan barn och vuxna och föreslår en ny term, TEXT SHADOW. Denna textskugga är mer komplex och dold bakom den uppenbara textytan, och den är tillgänglig för mer erfarna läsare, oberoende av ålder. Å andra sidan framhåller forskaren den dolda vuxna personens närvaro i barnlitteraturen. Han anser att så länge som vuxna håller fast vid antagandet att barn behöver en speciell litteratur, kommer den inte att förändras. 
It will be inherently educational but inherently ambivalent. It will be binaryoppositional: addressed to both children and the adults who select books for children; focalized through combinations of adult and childlike points of view; addressed to divided child readers; both simple and complex; representing both innocence and sublimated experience; both a source of knowledge and a source of pleasure; both subversive and conservative; both utopian and confirmative of normal reality. This is so because these characteristic markers are all variants of and manifestations of the basic opposition between adult and child implied by the very circumstance of adults writing for children. (Nodelman, 2008: 249)

Det finns ännu fler begrepp som pekar på samma fenomen. Ett är CROSSOVERLITTERATUR, lanserat av Sandra Beckett (2009, 2011), ett annat MULTIPLA MOTTAGARE, myntat av Emer O'Sullivan (2005), som distanserar sig såväl till Shavits modell som till Walls uppdelning - bägge två styrda av två ålderskategorier. Maria Nikolajeva tillämpar i Reading for learning (2014) den idag populära kognitiva teorin för att tolka barnlitteraturens egenart, och hon föreslår i linje med Nodelman en uppdelning i två kategorier som är oberoende av ålder: NOVICE READER (novisläsare) och EXPERT READER (expertläsare).

Av denna korta översikt framgår att det idag är svårt både att definiera barnlitteratur genom dess läsare och att uppnå konsensus inom forskarkåren i fråga om vem som egentligen är barnbokens huvudpublik samt hur denna publik läser barnböcker. Detta verkar härstamma från barnlitteraturens inherenta egenskap som lagts fram av Nodelman om att den är skapad för barn av vuxna. För att kringgå detta dilemma kan röster som på senare tid har hörts i Norden komma med en innovativ och fruktbar lösning.

\section{ALLÅLDERSLITTERATUR OCH DESS POTENTIELLA KONSEKVENSER}

Den i Norden populära termen ALLÅDERSLITTERATUR har varit närvarande sedan 1990-talet, och dess semantiska fält sammanfaller med det idag allt populärare begreppet crossover som införts betydligt senare (Ommundsen, 2015: 163). Denna typ av litteratur har presenterats nästan som ett manifest i En fanfar för bilderboken (2013). Det är en antologi där bilderboken hyllas och analyseras av en nordisk grupp innefattande Gro Dahle från Norge, Oscar K. Och Dorte Karrebæk från Danmark, Gunna Grähs och Ulla Rhedin från Sverige samt Maria Laukka från Finland. Bland många frågor runt bilderbokens utveckling och framtid läser man här nyskapande utsagor av författare och illustratörer just i relation till läsaren. Till exempel säger Shaun Tan, som belönades med ALMA priset 2011, att han inte skapar med tanke på någon mottagare, utan att det är konsten som skapar sin egen publik. Eva Lindström, en svensk illustratör och författare, berättar däremot att 
hon skriver för sig själv. Gro Dahle anser att det idag inte är lätt att dra någon skiljelinje mellan en barnbok och en vuxenbok. Hon uppfattar en bilderbok som en bok för alla åldrar:

[...] med bilderboken som allåldersbok finns det därmed både avancerade text-ochbild-språk för barn, poetiskt språk, expressivt eller minimalistiskt eller modernistiskt språk med jämförelser, metaforer, allegorier, allusioner. [...] det gör inte något om barnet tycker det är konstigt eller annorlunda eller förunderligt. [...] Därmed öppnas det för språklig lek och språkligt experimenterande i många dimensioner, för allt är tillåtet, allt är möjligt så länge det blir bra, så länge det är intressant, så länge det gör texten upplevelserik också för barnet. ${ }^{1}$ (Dahle, 2013: 108)

Det framgår av det här citatet att det som tidigare hette barnlitteratur nu kallas för allålderslitteratur och att barnet bara är en mottagare bland flera andra. Och denna litteratur är närvarande i Polen, eftersom Dahles böcker i samarbete med hennes man och dotter har blivit översatta till polska, vilket jag återkommer till nedan.

Detta nya allåldersperspektiv skulle inte bara kunna avsluta diskussionerna kring gränsen mellan barn- och vuxenböcker utan också kasta ett nytt ljus på översättningen av (barn)böcker. Förr fanns det tre väsentliga skillnader mellan barnboken och vuxenboken: högläsning, bildens roll samt den implicita läsarens, d.v.s. barnets, begränsade kompetens (Dymel-Trzebiatowska, 2013: 244). Det stod då klart att barnet inte var lika erfaret som en vuxen översättare, och att det inte hade lika stor encyklopedisk kompetens eller vetskap om litterära konventioner. Därför var det, i linje med Ritta Oittinens (2000) forskning, viktigt att ge måltextens implicita läsare en bild av barnet utifrån översättarens egna erfarenheter och iakttagelser. Den var en hybrid av det barn som översättaren själv en gång varit och nutida barn. Den mentala bilden var komplicerad och eklektisk men samtidigt mycket viktig för en rad olika val under översättningsprocessen. Främmandegörandet eller domesticeringen berodde på om översättaren litade på barnets kompetens eller inte. Men detta stämmer bara så länge det tas för givet att barnbokens mottagare måste vara ett barn. Om man accepterar att barnlitteratur har blivit allålderslitteratur, är det inte längre aktuellt att skapa en bild av en implicit barnläsare under översättningen av allåldersböcker. I så fall kan också en vuxen vara den implicita läsaren, och därför kan det bli ännu svårare att konstruera denna virtuella gestalt och konsekvent vända sig till den under ett långt och mödosamt översättningsarbete. $\AA ̊$ andra sidan kan det befria översättaren från begränsningar angående läsarens kompetens, och hen kan slutligen koncentrera sig på själva texten, dess innehåll och estetik i linje med tanken att "konsten skapar sin egen publik".

\footnotetext{
${ }^{1}$ Min fetstil.
} 
Idag är det inte heller lika självklart att det är illustrationer som är barnbokens särdrag. Och man tar hänsyn till att grafiska romaner eller t.o.m. bilderböcker för vuxna blivit allt populärare, är illustrationer inte heller aktuella som en egenhet hos barnboken. I så fall blir endast kriteriet högläsning, ibland kallat för tandemläsning, kvar som en specifik aspekt av barnboken, om... vi bortser från ljudböcker.

Däremot kan man anta att de nya tendenserna, inklusive förändringen av barnlitteratur till allålderslitteratur, endast avser några få högst konstnärliga verk, medan majoriteten av barnlitteratur fortfarande behållit sina barnläsare. Det verkar som att de flesta studierna kring barnlitteratur och dess översättning har fastnat för detta antagande.

\section{LYCKLIGT SLUT-GARANTI?}

Elżbieta Zarych (2016) skildrar förutsättningarna för att översätta barn- och ungdomslitteratur i Polen genom att förena forskarens, översättarens och redaktörens perspektiv. Hon framhåller lägets komplexitet och vuxnas mångfasetterade närvaro i en beslutsprocess som inte är konfliktfri. Detta utesluter den teoretiskt sett idealiska måltexten. Zarych åberopar sig bland annat på arbeten inom översättning av barnlitteratur, inklusive böcker skrivna av nordiska forskare. Hon diskuterar Riitta Oittinens implicita bild av läsaren och lägger till detta koncept en bild av barnet "sett genom förläggarens och den potentiella eller konkreta förälderns ögon" (Zarych, 2016: 213). Detta är inte nödvändigtvis samma bild som översättaren har.

Denna grundliga studie avslutas med konklusionen att polacker i gemen tyvärr fortfarande inte uppfattar barn som kompetenta läsare utan skyddar dem. Det påverkar i sin tur barnlitteraturen som av tradition ska vara skön, korrekt och med en lycklig avslutning. Därmed förväntas det att översättaren ska adaptera och "rena" texten, och att

de på något sätt ska mildra sorgliga fragment (förr hände det att de även ändrade på avslutningen), för att skapa en glad stämning och göra om verket så att det passar att läsa som godnattsaga. Man bagatelliserar behovet av att i en lindrig form bekanta barn med olika aspekter av livet samt att barnet i en viss ålder intresserar sig för hemska historier och farliga djur. (Zarych, 2016: 224)

Det här är en tankeväckande slutsats som redovisar den nuvarande situationen på bokmarknaden i Polen, eftersom den utgår från en författares rika och omfattande erfarenhet. Men samtidigt är det slående, att resonemanget har utelämnat betydelsefulla och omdebatterade nordiska barnböcker, vilka ofta är bilderböcker som har givits ut sedan cirka 2007. De representerar den andra kategorin i Zarychs typologi för översatta barn- och ungdomsböcker, d.v.s. 
"innovativa böcker, utvalda med hänsyn till innehållet eller illustrationerna (de har ofta blivit prisbelönta)" (Zarych, 2016: 214).

Det finns i Polen många översättningar från nordiska språk, där det inte förekommit några reduktioner, substitutioner eller andra former av adaptation som helt enkelt skulle ifrågasätta meningen med att överföra dem till polska. Dylika översättningstekniker skulle förstöra verket, eftersom dess essens ofta är en tabubelagd, svårhanterad tematik. Att manipulera den skulle krossa huvudmotivet och budskapet. Dessa översättningar gjordes i linje med Göte Klingbergs sammanfattande rekommendation kring purifikation i översättning av barnlitteratur:

I'm not saying that that publishers, readers and translators do not have the right to hesitate because of a book's set of values. But if one does not wish to convey the values (or emotional effects) of a foreign literary work, the simplest way is not to translate it at all. There is a nearly unlimited supply of fiction for children to choose from. (Klingberg, 1986: 52)

Några polska små förlag har beslutat att ge ut böcker som handlar om svåra känslor, om sorg, smärta och döden - ibland utan ett lyckligt slut.

\section{NORDMÄN PÅ DEN POLSKA BARNBOKSMARKNADEN}

Många nordiska bilderböcker som översatts till polska och omtalats både i forskning och medier har utkommit på förlagen Czarna Owca, Eneduerabe och Zakamarki samt FISO, Fonden för sociala initiativ. En serie, som exemplifierar att kontroversiella teman kommit just från Norden heter Bez tabu (Utan tabu), och ges ut av förlaget Czarna Owca (Svarta fåret). Böckerna omfattar 18 titlar varav de flesta skrivits av svenska författare. Seriens syfte var från början att beröra de teman som varit "viktiga, besvärliga, kontroversiella, som väckt förlägenhet och osäkerhet. De teman, som vi inte kan - eller skäms för - att prata om, eller sådana som vi helt enkelt är rädda för."2

Ungefär hälften av böckerna i serien Utan tabu har skrivits och illustrerats, av Pernilla Stalfelt som tagit upp svåra frågor t.ex. i Hårboken (1996, Mała książka o wtosach 2010), Bajsboken (1997, Mała ksiażka o kupie 2008), Dödenboken (1999, Mała książka o śmierci 2008), Kärleksboken (2001, Mała książka o miłości 2010), Våldboken (2005, Mała ksiażka o przemocy 2008). "Barn är jätteintresserade av sånt, liksom spöken [...] Jag vet inte hur bra det egentligen är att skydda barn från otäcka bilder som visas på tv etc. Det kan bli en chock för dem den dag de ska konfronteras med verkligheten. Betydligt

${ }^{2}$ Citatet kommer från förlagets gamla webbsida (förr hette det Jacek Santorski) som inte längre används: http://www.jsantorski.pl/inf.php?id=nr387. 
viktigare är det att vuxna hjälper barnen bearbeta det de ser och hör."”, skriver Stalfelt ${ }^{4}$.

Andra svenska faktaböcker inom serien tar upp ännu mer provocerande teman: Gud finns nog inte (2008, Boga przecież nie ma 2010) av Patrik Lindenfors, Min lilla röda: allt du vill veta om mens (2008, Mała książka o miesiączce 2009) av Marie Oskarsson samt Lilla snoppboken (2002, Wielka księga siusiaków 2009) och Lilla snippaboken (2004, Mała księga cipek 2010) av Dan Höjer och Gunilla Kvarnström. I Polen har Lilla snippaboken en extra, censurerad version där man har tagit bort en bild av en korsfäst kvinna, vilket är ett tecken på en ideologisk purifiering enligt Göte Klingberg. Fyra titlar inom Utan tabu skrevs efteråt av polska författare som inspirerats av sina svenska kollegor. De fortsatte diskussionen runt sådana ämnen som homofobi, abort, rasism och tolerans.

EneDueRabe fokuserade både på svenska och norska verk medan Zakamarki endast inriktade sig på svenska titlar ${ }^{5}$. Många av de nya böckerna handlade om döden och andra frågor som ofta betecknas som "svarta", t.ex. ensamhet, sjukdom, våld och dysfunktionella familjer. Bland de svenska bilderböckerna vill jag uppmärksamma två som behandlar just döden: Adjö, herr Muffin! (2002, Żegnaj, panie Mufinie! 2008) av Ulf Nilsson och Anna-Clara Tidholm, vilken fått Augustpriset, och Mitt svarta liv (2007, Moje czarne życie 2012) av Amanda Eriksson. Dessa böcker kom ut på EneDueRabes förlag vars ambitioner och planer framgår av deras webbsida: "Noggrant och med passion letar vi i hela världen efter böcker som tar upp svåra, viktiga, ofta tabubelagda ämnen, böcker som visar en annan kultur och som är fyllda med humor, barnglädje och spontanitet."7

Adjö, herr Muffin! handlar om ett marsvin som har fått ont i magen och kommer att dö. Han är rätt gammal nu men har haft ett bra liv: med eget hus, fin familj, god mat, äventyr och ett ständigt kelande. Hans liv och död presenteras både $\mathrm{i}$ text och bild med respekt och allvar, samtidigt som beskrivningen av djuret blir lite komisk i sina "marsvinsproportioner". Som ett exempel kan man nämna en lista som bland annat uppger att Muffin sammanlagt ätit 2555 maskrosor eller en upplysning om att han när han var ung och stark, kunde kånka

\footnotetext{
${ }^{3}$ Hämtat från: http://www.barnensbibliotek.se/tabid/336/Default.aspx (13.06.2015).

${ }^{4}$ Polska recensenter har haft olika åsikter om Stalfelts första böcker i Polen: somliga har varit positiva, t.ex. i tidskriften Ryms, medan andra varit ganska kritiska, t.ex. i Guliwer (Kulus 2009), och jag tror att denna polarisering avspeglar reaktionerna hos en bredare läsarkrets.

5 Åren 2007-2011 var det en filial till Norstedts förlag.

${ }^{6}$ Här hänvisar jag till beteckningen "svart" som var den dominerande termen i SBI:s årsrapport 2009: "Böckernas gestalter har att såväl bearbeta och begränsa som att bejaka de svarta och dunkla sidorna av den helhet som en sammansatt människa består av." Hämtat från: http://www.sbi.kb.se/Documents/Public/Bokprovning/Dokumentation/Argang_2009.pdf (14.06.2015)

${ }^{7}$ Hämtat från: http://eneduerabe.eu/o-nas/ [08.08.16].
} 
på stora gurkor - med en bild på väggen som bevis. Det är en ärlig bok som handlar om döden utan några försköningar och som hjälper läsaren att bearbeta sorg och konstatera att döden inte är så hemsk. Det fiktiva barnet, Muffins ägare, som måste genomlida hans bortgång, slår fast: "Visst är det så att antingen är döden en vila och då är döden ingenting att vara rädd för. Eller så förs man någonstans till ett evigt liv och lever där i lycka. Och då är döden något att längta efter!" (Nilsson, Tidholm, 2002) ${ }^{8}$

Den andra boken, Mitt svarta liv av Amanda Eriksson som både författare och illustratör, berör samma tema men på ett helt annat sätt. En liten flicka går på sin mormors kusins begravning och iakttar allt som finns och som händer $\mathrm{i}$ kyrkan med förundran men utan några djupare känslor. Sedan leker hon begravning med sin morfar, då de begraver en död mus, vilket antagligen har till syfte att få barnet att vänja sig vid själva fenomenet av döende och att acceptera det som något helt naturligt. Förberedelserna inför musbegravningen har en instruktiv karaktär i motsats till Adjö, herr Muffin! som är mycket känslomässig och rörande.

Den norska duon Dahle-Nyhus tar också upp svåra frågor i sina bilderböcker för barn; där uttrycks våld, alkoholism, depression och skilsmässa i en högst estetisk form. Gro Dahle skriver explicit att det är kulturella förutsättningar som är en gynnsam miljö för en så nyskapande produktion: "I Norge är det inte det söta och rara och snälla som är idealet. [...] I Norge är det inte försäljningen som räknas, utan den litterära kvaliteten, den konstnärliga nivån, den personliga rösten, det levande språket, originaliteten." (Dahle, 2013: 109)

Bland det norska parets representativa verk finns några titlar som utkommit i Polen: Pappa! (1998, Tato! 2008), Snill (2002, Grzeczna 2010), Håret till mamma (2007, Wtosy mamy 2010), Sinna man (2003, Zly Pan 2013). I Pappa! kan den lilla pojken Tommy inte somna utan fantiserar om sin frånvarande far. Hans projektioner kan beundras i vackra illustrationer föreställande en jättestor fantastisk figur av fadern och den lille pojken. Genom små symboliska detaljer ifrågasätter bilden texten: ett hål i pappans strumpa och en taggtråd syftar på att den ideala gestaltningen i ord inte är sann. Snäll $l^{9}$ handlar om Lussi, den lydiga och duktiga flicka som varit så snäll att hon gjort sig osynlig. Flickan försvann in i en vägg för att slutligen frigöra sig i en omvandlad form: rufsig i håret, $\mathrm{i}$ smutsig klänning och med fingret i näsan. I Mammas hår ${ }^{10}$ måste den lilla Emma ta hand om sin älskade mor som drabbats av en depression. Mammans sjukdom gestaltas symboliskt genom hennes fina hår som blir rufsigt, tovigt och matt. Den arge ${ }^{11}$ skildrar Bojs rädsla för pappan som efter att han druckit

\footnotetext{
${ }^{8}$ Jag uppger inte sidan, eftersom bilderböcker inte sidnumreras.

${ }^{9}$ Det är bokens svenska titel. Den utkom i Sverige på Bokförlaget Daidalos år 2008.

${ }^{10}$ Det är bokens svenska titel. Den utkom i Sverige på Bokförlaget Daidalos 2012.

${ }^{11}$ Det är bokens svenska titel. Den utkom i Sverige på Bokförlaget Daidalos 2009.
} 
alkohol förvandlas till ett grymt troll. Nyhus karaktäristiska stil, med runda linjer och underifrånperspektiv bidrar till den hotfulla stämningen.

Gro Dahles nyaste texter illustreras av hennes dotter Kaia Dahle Nyhus, och till de böcker som kommit ut i Polen av den nya familjeduon hör Krigen ${ }^{12}$ från 2013 (Wojna, 2016). Den handlar om föräldrars skilsmässa från Ingas perspektiv. Kriget, som hon tidigare känt till endast från tv och tidningar, har med sina grymma attribut som stridsvagnar, vapen och bränder flyttat in i flickans hem. De stridande är mamman och pappan som slutligen bestämmer sig för att skiljas, och då förvandlas Inga till en soldat, som ibland kämpar på den enes, ibland på den andres sida. Hon flyttar också från det ena hemmet till det andra med sina småsyskon i släptåg, och ingen bryr sig om henne. Ingen ser att hon slutat äta och det hjälper inte ens att hon skadar sig själv. Det är en tung och känsloladdad historia som inte använder sig av ordet skilsmässa. Gro Dahle arbetar som vanligt med ett metaforiskt språk som är mycket poetiskt och som på ett perfekt sätt avspeglar protagonistens perspektiv. Stämningen förstärks av Kaia Dahles naivistiska illustrationer som bildar explosiva kontraster genom att tillämpa fyra starka färger: orange och violett eller blått och gult.

Följande intressanta exempel är s.k. genusvänliga bilderböcker: Kenta och barbisarna (2007, Igor i lalki 2009) och Lill-Zlatan och morbror raring (2006, Zlatanka i ukochany wujek 2012) av Pija Lindenbaum. Båda böckerna har utkommit på förlaget Zakamarki och tar upp frågan om hur en flicka och en pojke ska vara. Kenta är bra på fotboll, men samtidigt vill han leka med barbiedockor. På dagis föredrar han flickornas sällskap och leker prinsesslekar, trots att alla killar vill ha med honom i sitt lag. När de andra pojkarna upptäcker att Kenta umgås med flickorna, mobbar de honom inte. I stället klär alla grabbarna också ut sig till prinsessor, och alla leker tillsammans. Boken ifrågasätter den rådande ordningen som handlar om könsfördelning och visar att leken inte känner till några gränser.

Protagonisten i Lill-Zlatan och morbror raring är en flicka, kallad LillZlatan, eftersom hon är tokig i fotboll. Hon syns även på en bild i boken om Kenta, vilket är ett populärt metafiktivt grepp bland bildberättare som vill visa en koppling mellan sina verk. Lill-Zlatan är förtjust i sin morbror Tony, som hon ofta leker med. Men plötsligt dyker Steve upp och flickan blir svartsjuk. Steve är Tonys partner, men det spelar ingen roll för barnet att det handlar om ett homosexuellt förhållande. Lill-Zlatan och morbror raring berättar snarare en historia om att hantera svartsjuka. I Lindenbaums bägge böcker accepteras avvikande inställningar och beteenden, så man kan säga att de huvudsakligen handlar om tolerans för individualitet och "annorlundahet".

Åren 2008-2009 gav FISO ut fyra norska bilderböcker, varav två handlade om döden och två om svåra känslor. Dödens tematik berördes på två helt olika

${ }^{12}$ På svenska heter boken Kriget och utkom på Bokförlaget Daidalos 2014. 
sätt - realistiskt respektive metaforiskt - i Tror du pappa gråter? från 2008 (Czy tata płacze?, 2009) av Hilde Ringen Kommedal med Tone K. Lilengs illustrationer samt Himmelen bak huset från 2008 (Niebo za domem, 2009) av Gaute Heivoll och Øyvind Lauvdahl. Stian Hole tog däremot upp diskussionen kring sådana ämnen som den första skoldagen och åldrandet ur en sexårings perspektiv i boken Garmanns sommer ${ }^{13}$ från 2006 (Lato Garmanna, 2008). Den belönades med Bologna Ragazzi Award 2007 som den första helt digitalt skapade bilderboken i prisets historia. Fotomontage av många fotografier ger både Garmanns och hans tanters ansikten ett universellt utryck, och alla kan känna sig igen i dem. Bilderna genomsyras av symboler, och i samspel med texten förvandlar de denna bok till en rikt nyanserad existentiell berättelse. Holes andra bok Garmanns gate ${ }^{14}$ från 2008 (Ulica Garmanna, 2009) handlar om en otursdag i den sjuårige Garmanns liv, vilken tack vare hans modiga beteende slutar med en riktig vänskap.

\section{BEREDDA PÅ PARADIGMSKIFTE?}

Tack vare de ovan nämnda verken, som bara är några exempel på en bredare tendens, har den moderna nordiska ${ }^{15}$ barnlitteraturen etiketterats i Polen som djärv, nyskapande, postmodern och tabubrytande ${ }^{16}$. Det blev möjligt tack vare några förlags initiativ, när de för sedan cirka 2007 beslutade att införa svåra och även kontroversiella ämnen på den polska bokmarknaden och skapa en motvikt mot det en aning ensidiga utbudet. Som det framgår av Elżbieta Zarychs forskning dominerar en föråldrad barnbild i Polen. Denna bild har inte hunnit ikapp det moderna verkliga barnet som fått en allt större tillgång till information via Internet och globalisering, eftersom den fortfarande har förväntningar på att översättare ska manipulera, purifiera och försköna. Men polska översättningar av skandinaviska (barn)böcker motsäger denna tendens - de består av pinsamma motiv, öppna/olyckliga avslutningar och ambivalenta karakteriseringar, som den beskyddande vuxen teoretiskt sett borde bespara barnet. Att manipulera dem skulle innebära att undergräva deras innersta väsen och därmed - i linje med Klingbergs uppfattning - meningen med att översätta dem.

${ }^{13}$ Boken utkom i Sverige med titeln Hermans sommar i Alfabeta 2008.

${ }^{14}$ Boken utkom i Sverige med titeln Hermans och eldsvådan i Alfabeta 2009.

${ }^{15}$ Svenskarna har varit på sistone rätt kritiska mot sin egen bilderboksproduktion. Det har hörts röster i recensioner att det råder "bästsäljarism" i Sverige och att de nordiska grannarna nu skapar högst konstnärliga och suggestiva böcker - som exempelvis Gro Dahle och Svein Nyhus från Norge samt Oscar K. och Dorte Karrebæk från Danmark. Se t.ex. "Barnböcker med död" av Ulla Rhednin, publicerad 12.05.2009: http://www.dn.se/dnbok/barnbocker-med-dod/ [15.08.16].

16 Till detta rykte ledde Svarta fårets serie Utan tabu, projektet (och sen boken Tabu w literaturze i sztuce dziecięcej) Tabu i barnkonsten, som drevs av Danska kulturinstitutet i Polen 2011, forskares bidrag (t.ex. Dymel-Trzebiatowska 2012, Cackowska 2013,) samt en rad utsagor och artiklar i medierna (Kulus 2009, Petryna 2010, Skibińska 2010). 
Barnlitteratur är idag ett omfattande och svårdefinierat begrepp som inte längre kan preciseras genom att kategorisera en implicit läsare. I det avseendet har ett antal forskare föreslagit flera intressanta perspektiv som fått åtskilliga beteckningar som AMBIVALENS, DUBBELT TILLTAL, MULTIPLA MOTTAGARE och TEXTSKUGGA. Men kanske blir den nordiska ALLÅLDERSLITTERATUREN eller den mer internationella CROSSOVERLITTERATUREN så småningom en lösning på det rätt länge olösbara problemet.

Om flera böcker förlorar sina implicita läsare, betingat av ålderskategoriseringen, blir det också nödvändigt att rekonceptualisera de grundläggande förutsättningarna för översättningsprocessen. De polska översättningarna av skandinaviska (barn)böcker har varit fria från större adaptationer ${ }^{17}$ men de har antagligen gjorts med tanke på barnet som huvudläsare. Nutida författare och illustratörer i Skandinavien understryker allt oftare att de skapar för alla. Ska deras böcker också översättas för alla? Är översättarna beredda att arbeta med böcker som har barnestetik och barnboksformat trots att de är riktade till vuxna? Är det väsentligt för dem, eller antar de att läsaren bli en annan beroende av kulturbetingelser? Långsiktiga svar på dessa frågor skulle verkligen kunna berika översättningsteorin.

\section{LITTERATURFÖRTECKNING}

Beckett, S. (2009). Crossover fiction: global and historical perspectives. New York: Routledge. Beckett, S. (2011). Crossover picturebooks: a genre for all ages. New York: Routledge.

Cackowska, M. (2013). Ideologie dzieciństwa a/i tabu w książkach obrazkowych dla dzieci. Opuscula Sociologica 201/3, 19-30.

Dahle, G. (2013). Bilderböcker som lekplats. I: U. Rhedin, K. Oscar, L. Eriksson (red.) En fanfar för bilderboken (s. 101-119). Stockholm: Alfabeta.

Dymel-Trzebiatowska, H. (2012). Czy Skandynawowie łamią tabu? Najnowsza skandynawska literatura dla dzieci w Polsce. I: G. Tomaszewska et.al. (red.), Jestem - więc czytam. Między pragmatyzmem z wolnościa (s. 303-313).. Gdańsk: Wydawnictwo UG.

Dymel-Trzebiatowska, H. (2013). Translatoryka literatury dziecięcej. Analiza przekładu utworów Astrid Lindgren na język polski. Gdańsk: Wydawnictwo Uniwersytetu Gdańskiego.

Evans, J (red.). (2015). Challenging and Controversial. Creative and Critical Responses. New York and London: Routledge.

Kulus, M. (2009). Czy po śmierci jestem hot dogiem?, Guliwer. Czasopismo o książce dla dziecka 2009/3, 74-75.

Nikolajeva, M. (1998). Barnbokens byggklossar. Lund: Studentlitteratur.

Nikolajeva, M. (2014). Reading for Learning: Cognitive approaches to children's literature. Amsterdam, Philadelphia: John Benjamins Publishing Company.

Nodelman, P. (2008). The Hidden Adult. Defining Children's Literature. Baltimore: The Jones Hopkins University Press.

Oittinen, R. (2000). Translating for Children. New York: Garland.

Ommundsen, Å-M. (2014). Picturebooks for Adults. I: B. Kümmerling-Meibauer (red.), Picturebooks. Representation and Narration (s. s. 17-35). New York and London: Routledge.

${ }^{17}$ Med mindre adaptationer menar jag t.ex. tillämpning av diminutiver eller översättning av egennamn som oftast blivit anpassade för barn. 
Ommundsen, $\AA$-M. (2015). Who are these picturebooks for? Controversial picturebooks and the question of audience. I: J. Evans (red.). Challenging and Controversial Picturebooks. Creative and Critical Responses (s. 71-93). New York and London: Routledge.

O'Sullivan, E. (2005). Comparative children's literature. Abindon: New York.

Petryna, M. (2010). Polemika. Ryms. Kwartalnik o ksiązkach dla dzieci i młodzieży 2010/10, 28-29.

Skibińska, E. (2010). Wielka księga siusiaków. Wielka księga cipek. Ryms. Kwartalnik o ksiązkach dla dzieci i młodzieży 2010/9, s. 16.

Sochańska, B. (2012). Tabu w literaturze i sztuce dziecięcej. Poznań: Media Rodzina.

Shavit, Z. (1986). Poetics of Children's Literature. Athens \& Georgia: University of Georgia Press.

Wall, B. (1991). The Narrator's Voice, The Dilemma of Children's Fiction. London: McMillan.

\section{Hanna Dymel-Trzebiatowska}

Uniwersytet Gdański

Instytut Skandynawistyki

ul. Wita Stwosza 51

80-308 Gdańsk

Poland

filhdt@univ.gda.pl 